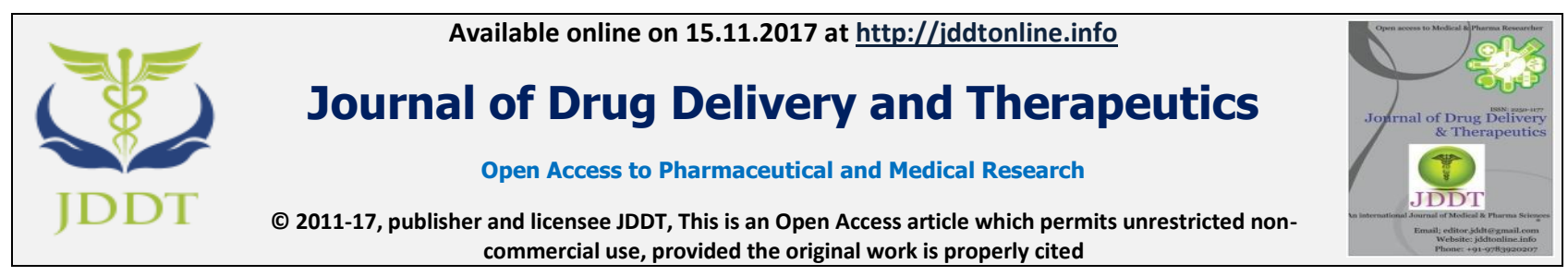

Open $\odot$ Access

Research Article

\title{
TRANSDERMAL PATCH OF RAMIPRIL LOADED CHITOSAN NANOPARTICLES DISPERSED IN CARBOPOL GEL
}

\section{Yerikala Ramesh, Vadhireddy Sireesha*}

Department of pharmaceutics, Ratnam Institute of pharmacy, Pidathapolur (V\&P), Muthukur (M), SPSR Nellore (Dist) 524346, Andhra Pradesh, India.

\section{ABSTRACT}

The main aim to improve the systemic bioavailability of Ramipril by the design of transdermal drug delivery based on chitosan nanoparticles dispersed into gels. When chitosan nanoparticles dispersed into gels consisting of poloxamer and carbopol the resulting formulation exhibited thixotropic behavior with a prolonged drug release properties. Our study demonstrated that the designed nanoparticles gel transdermal delivery system has a potential to improve the systemic bioavailability and the therapeutic efficacy of Ramipril loaded chitosan nanoparticles dispersed in carbopol gels. There is no incompatibility between drug and polymers by performing FTIR and DSC. To characterize the rate controlling membrane of transdermal patches. The thickness ranged between TNPGF1 to F9 $0.11 \pm 0.05 \mathrm{~mm}$ to $0.19 \pm 0.07 \mathrm{~mm}$, which indicates that they are uniform in thickness. The different batches of formulations weights variations were relatively good uniformity of weight variations among the various batches was observed, with all formulations and ranged from $1.40 \pm 1.2 \%$ to $1.78 \pm 2.0 \%$. The flatness study showed that all the formulations had the same strip length before and after their cuts, indicating $99 \%$ flatness. The tensile strength of the TNPGF1 to TNPGF9 shows the $10.14 \pm 1.19$ to $12.78 \pm 2.45$ shows the excellent viscosity. The total amount of drug is present in the transdermal patches of TNPGF1 to TNPGF9 was found to be $90.5 \pm 0.3 \%$ to $98.5 \pm 0.1 \%$. In-vitro Franz's diffusion drug Release Studies of among all formulations best formulation TNPGF6. The drug release through the transdermal patches of Ramipril, follows first order kinetics with diffusion controlled mechanism.

Keywords: Ramipril, Nanoparticles, Gels, Folding endurance, Tensile strength.

Article Info: Received 03 Sep, 2017; Review Completed 18 Oct, 2017; Accepted 03 Nov, 2017; Available online 15 Nov, 2017

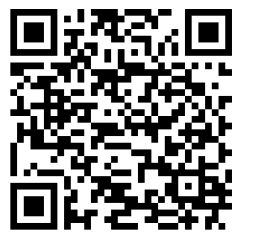
SPSR Nellore (Dist) 524346, A.P., India. Email: vadhireddy.sireesha@gmail.com, Mobile No: 7032024478

\section{Cite this article as:}

*Address for Correspondence

Ramesh Y, Sireesha V, Transdermal patch of ramipril loaded chitosan nanoparticles dispersed in carbopol gel, Journal of Drug Delivery and Therapeutics. 2017; 7(6):56-65 DOI: http://dx.doi.org/10.22270/jddt.v7i6.1523

Yerikala Ramesh, Department of pharmaceutics, Ratnam Institute of pharmacy, Pidathapolur (V\&P), Muthukur (M),

\section{INTRODUCTION}

Transdermal drug delivery system: At present, the most common form of delivery of drugs is the oral route. While this has the notable advantage of easy administration, it also has significant drawbacks namely poor ability due to hepatic metabolism (first pass) and the tendency to produce rapid blood level spikes (both high and low), leading to a need for high and/or frequent dosing, which can be both cost prohibitive and inconvenient ${ }^{1}$.

\section{Advantages}

1. Transdermal drug delivery can be used as an alternative delivery system for patients who cannot tolerate oral dosage forms.
2. Avoid the first pass effect e.g. transdermal nitroglycerin. It is rapidly metabolized by the liver when taken orally ${ }^{2}$.

3. Drug therapy may be terminated rapidly by removal of the application from the surface of the skin.

4. It is of great advantage in patients who are nauseated or unconscious.

5. Allows continued drug administration permitting the use of a drug with short biological half-life.

\section{Disadvantages}

1. The drug, the adhesive or other excipients in the patch formulation can cause erythema, itching, and local edema. 
2. The barrier function of the skin changes from one site to another on the same person, from person to person and also with age ${ }^{3}$.

3. Some drugs e.g. scopolamine transdermal patch placed behind the ear, it is uncomfortable.

4. Adhesion may vary with patch type and environmental conditions.

5. Drugs that require high blood levels cannot be administered.

\section{MATERIALS AND METHODS}

The pure drug of Ramipril was obtained from Hetero drug Limited, Hyderabad and excipiens like Chitosan, Poloxamer, HPMC, Pentasodium tripolyphosphate, Dimethyl sulfoxide, Carbopol, Acetic acid, dimethyl sulfoxide obtained from Pharmaceutical Pvt Ltd, Navi Mumbai.

Formulation of Ramipril Loaded chitosan nanoparticles dispersed in carbopol gel:

\section{Preparation of Nanoparticles:}

Nanoparticles were Prepared by the ionic gelation technique at room temperature with combinations of different ratio of chitosan as shown in table and Pentasoidum tripoly phosphate. Chitosan was dissolved in acetic acid solution adjusted to $\mathrm{pH} 4.5$ and TPP was dissolved in Milli-Q water (The system monitors the ion concentration by measuring the electrical resistivity of the water). TPP solution was added drop wise to an equal volume of chitosan solution under magnetic stirring at $650 \mathrm{rpm}$ over $60 \mathrm{~min}$. Ramipril loaded chitosan nanoparticles were prepared by the same method mentioned above, but that the appropriate amount of Ramipril was dissolved in chitosan solution before the dropwise addition of TPP solution ${ }^{4}$.

\section{Formulation of gels:}

Poloxamer gels were prepared by using the cold technique. Poloxamer was slowly added into certain volume of cold Milli $\mathrm{Q}$ water $\left(5-10{ }^{\circ} \mathrm{C}\right)$ with constant stirring for $60 \mathrm{~min}$ at $650 \mathrm{rpm}$. Additional amount $\mathrm{Of}$ Cold Milli-Q water was added to the solution at 30 min to make up to the volume ${ }^{5}$. Poloxamer solutions were kept in the refrigerator $\left(4-5{ }^{\circ} \mathrm{C}\right)$ over night then kept at room temperature for a further 24 h Carbopol $940(1 \%$ and $2 \%$ w/v) gels were prepared by dispersing appropriate amount of carbopol into certain volume of Milli-Q water At room temperature with constant stirring for $60 \mathrm{~min}$ at $650 \mathrm{rpm}$. Milli-Q water was added to the solution at $30 \mathrm{~min}$ to Make up the volume to the total amount. Carbopol gels were kept at room temperature for $24 \mathrm{~h}$. Poloxamer and carbopol combination gels were prepared with similar methods as above. Both were stirred at $650 \mathrm{rpm}$ for $60 \mathrm{~min}^{6}$. At $30 \mathrm{~min}$, the two were mixed and Milli Q Water was added to the mixture with stirring to make up the volumes to the total amount. These gels were kept at room temperature for $24 \mathrm{~h}$.

\section{Formulation of nanoparticles / gels transdermal delivery Systems:}

The prepared Ramipil loaded chitosan naoparticles dispersed in carbopol gels incorporated in transdermal molds and the characteristics of resultant transdermal delivery systems was evaluated ${ }^{7}$.

Table 1: Formulation design of Transdermal Patches of Ramipril Loaded chitosan nanoparticles dispersed in carbopol gels TNPGF1 to TNPGF5

\begin{tabular}{|l|l|l|l|l|l|}
\hline Ingredients & TNPGF1 & TNPGF2 & TNPGF3 & TNPGF4 & TNPGF5 \\
\hline Ramipril (gms) & 1 & 1 & 1 & 1 & 1 \\
\hline Chitosan (gms) & 2 & 2 & 2 & 2.5 & 2 \\
\hline Polaxamer (gms) & 5 & 5 & 5 & 4 & 4 \\
\hline HPMC (gms) & 2 & 1 & 0.5 & 1 & 1 \\
\hline Pentasodium tripolyphosphate (gms) & 0.5 & 0.5 & 0.5 & 0.5 & 0.5 \\
\hline Dimethyl sulfoxide (ml) & 1 & 1 & 1 & 1 & 1 \\
\hline Carbopol (gms) & 2 & 2 & 2 & 2 & 2 \\
\hline Acetic acid (ml) & 15 & 15 & 15 & 15 & 15 \\
\hline
\end{tabular}

Table 2: Formulation design of Transdermal Patches of Ramipril loaded chitosan nanoparticles dispersed in carbopol gels TNPGF6 to TNPGF9

\begin{tabular}{|l|l|l|l|l|}
\hline Chemical name & TNPGF6 & TNPGF7 & TNPGF8 & TNPGF9 \\
\hline Ramipril (gms) & 1 & 1 & 1 & 1 \\
\hline Chitosan (gms) & 3 & 1 & 1 & 1 \\
\hline Polaxamer (gms) & 4 & 3 & 3 & 3 \\
\hline HPMC (gms) & 1 & 1.5 & 1.5 & 1.5 \\
\hline Pentasodium tripolyphosphate (gms) & 0.5 & 0.5 & 0.5 & 0.5 \\
\hline Dimethyl sulfoxide (ml) & 1 & 1 & 1 & 1 \\
\hline Carbopol (gms) & 2 & 2 & 2 & 2 \\
\hline Acetic acid (ml) & 15 & 15 & 15 & 15 \\
\hline
\end{tabular}


Evaluation studies:

\section{Drug-Polymer Compatibility studies}

FT-IR Spectra: Prior to the development of the dosage forms, infrared spectra of the physical mixture of the Ramipril, polymers individually and the mixture of drug and polymer were taken. The drug-Polymer Interaction were studied by FTIR spectrometer, shimadzu $8400 \mathrm{~S}$ $2 \% \mathrm{w} / \mathrm{w}$ of the sample with respect to a potassium Bromide mixed with drug $\mathrm{KBr}^{8}$.

Differential scanning calorimetry: The output of a DSC is a plot of heat flux (rate) versus temperature at a specified temperature rate ${ }^{9}$. DSC provides information about the physical properties of the sample as crystalline or amorphous nature and demonstrates a possible interaction between drug and polymers in formulations.

Physicochemical evaluation of films:

Thickness of the Patch: The thickness of patches was measured at three different places using a micrometer (Mitutoyo Co., Japan) and mean values were calculated 10

Weight Variation: The patches were subjected to mass variation by individually weighing randomly selected patches ${ }^{11}$. Such determination was carried out for each formulation.

Moisture Content: The patches $(n=3)$ were weighed individually and kept in a desiccator containing calcium chloride at $37{ }^{\circ} \mathrm{C}$ for $24 \mathrm{hrs}$. The final weight was noted when there was no change in the weight of individual patch ${ }^{12}$. The percentage of moisture content was calculated as a difference between initial and final weight with respect to final weight.

Moisture Uptake: A weighed film kept in desiccators at $40{ }^{\circ} \mathrm{C}$ for $24 \mathrm{~h}$ was taken out and exposed to two different relative humidity of $75 \% \mathrm{RH}$ (saturated solution of sodium chloride) and 93\% RH (saturated solution of ammonium hydrogen phosphate) in two different desiccators respectively at room temperature then the weights were measured periodically to constant weights ${ }^{13}$.

Flatness: Longitudinal strips were cut out from the prepared medicated film the lengths of each strip were measured. Then variation in the length due to the nonuniformity in flatness was measured ${ }^{14}$. Flatness was calculated by measuring constriction of strips and a zero percent constriction was considered to be equal to a hundred percent flatness.

$$
\text { Constriction }(\%)=\frac{L 1-L 2}{L 2} \times 100
$$

Where,

\section{L1 - initial length of strip}

L2 - final length of strip.

Determination of Tensile Strength: In order to determine the elongation as a tensile strength, the polymeric patch was pulled by means of a pulley system weights were gradually added to the pan to increase the pulling force till the patch was broken ${ }^{15}$. The elongation i.e. the distance traveled by the pointer before break of the patch was noted with the help of magnifying glass on the graph paper, the tensile strength was calculated as $\mathrm{kg}$ $\mathrm{cm}^{2}$.

Folding Endurance: This was determined by repeatedly folding one film at the same place till it broke. The Timber of times the film could be folded at the same place without breaking gave the value of folding endurance ${ }^{16}$.

Water Vapour Transmission (WVT) Rate: WVTR is defined as the quantity of moisture transmitted through unit area of film in unit time. The film was fixed over the brim of a glass vial, containing $3 \mathrm{~g}$ of fused calcium chloride as desiccant, with an adhesive tape ${ }^{76}$. The vial was weighed and kept in desiccators containing saturated solution of potassium chloride to provide relative humidity of $84 \%$. The vial was taken out and weighed at every $24 \mathrm{hrs}$ interval for a period of $72 \mathrm{hrs}{ }^{17}$. The water vapour transmission rate was calculated from the plots of amount of water vapour transmitted versus time.

Drug Content Determination: The patches at $1 \mathrm{~cm} 2$ were cut and added to a beaker containing $100 \mathrm{ml}$ of Phosphate buffered solution of $\mathrm{pH}$ 7.4. The medium was stirred with a Teflon coated magnetic bead for $5 \mathrm{hrs}{ }^{18}$. The solution was later filtered and analyzed for drug content with proper dilution at $219 \mathrm{~nm}$ spectrophotometrically.

In vitro Franz's diffusion studies of Transdermal patches of Ramipril though chitosan nanoparticles dispersed in carbopol gels: In vitro release studies can be performed in a modified Franz diffusion cell over a period of time 12 hours. At specific time intervals, aliquots of samples containing the released drug are taken from the acceptor compartment and are quantified using a suitable method ${ }^{19}$. The fabricated film was placed on the rat skin and attached to the diffusion cell such that the cell's drug releasing surface towards the receptor compartment which was filled with phosphate buffer solution of $\mathrm{pH} 7.4$ at $37 \pm 1{ }^{\circ} \mathrm{C}$. The elution medium was stirred magnetically. The aliquots $(5 \mathrm{ml})$ were withdrawn at predetermined time intervals and replaced with same volume of phosphate buffer of $\mathrm{pH}$ 7.4. The samples were analyzed for drug content using UV spectrophotometer at $219 \mathrm{~nm}$.

Mathematical modeling of release kinetics ${ }^{20}$ : The in vitro drug release data were fitted to various release kinetic models namely first order (Ln Qo- k1 t), zeroorder $\mathrm{Q}=\left(\mathrm{Q} o \_\right.$ko $\left.\mathrm{t}\right)$, Higuchi equations $(\mathrm{Q}=\mathrm{kh} 2) 1 / 2$, Korsemeyer-Peppas $(\log Q t v s \log \mathrm{t})$,

Where

$\mathrm{Qt}$, is the cumulative amount of drug released at time $\mathrm{t}$ and

$\mathrm{Q}_{0}$ is the initial amount of drug present in Microspheres.

Ko is the zero order release rate constant, $\mathrm{k} 1$ is the first order release rate constant, and $\mathrm{kh}$ is the diffusion rate constant. 


\section{RESULTS AND DISCUSSION}

\section{Compatability Studies:}

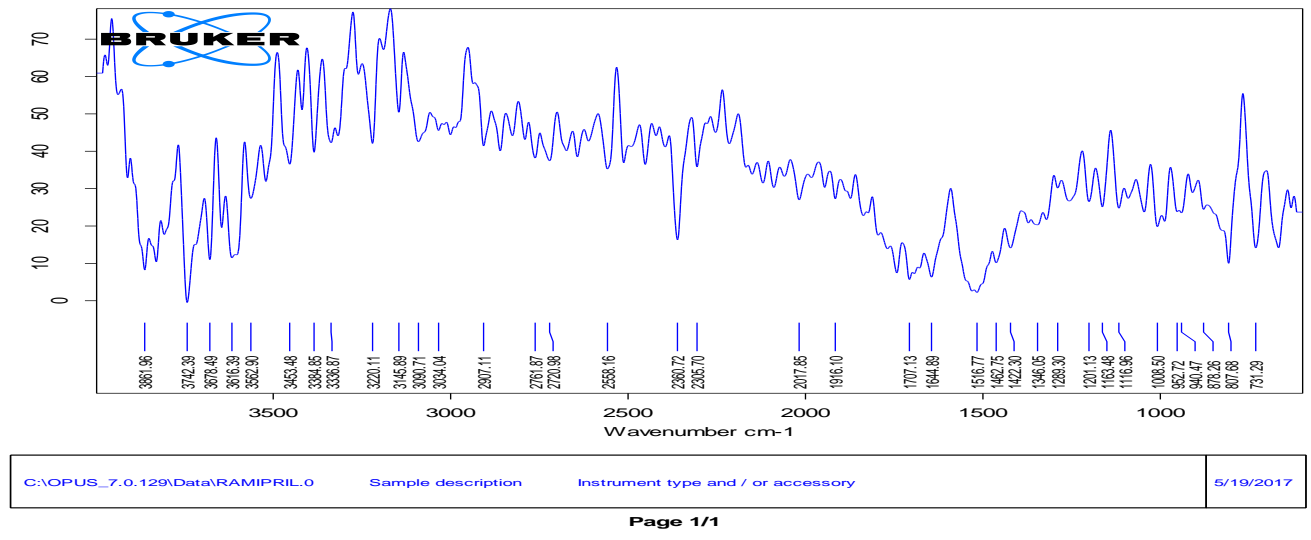

Figure 1: FTIR Spectra of Ramipril (pure drug)

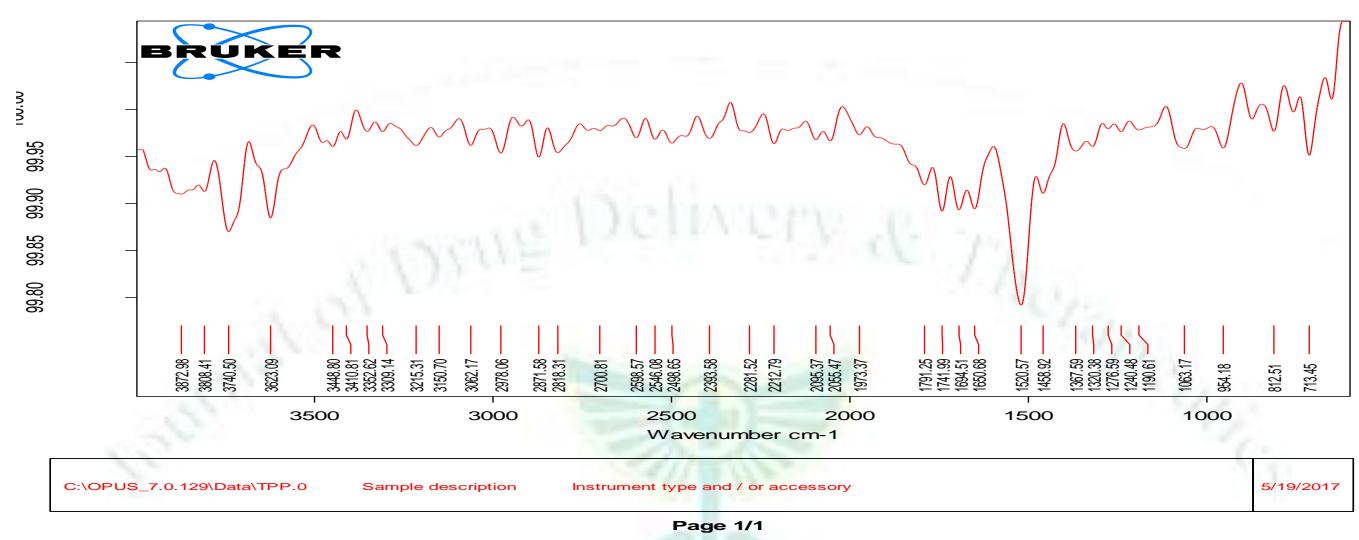

Figure 2: FTIR Spectra of TPP

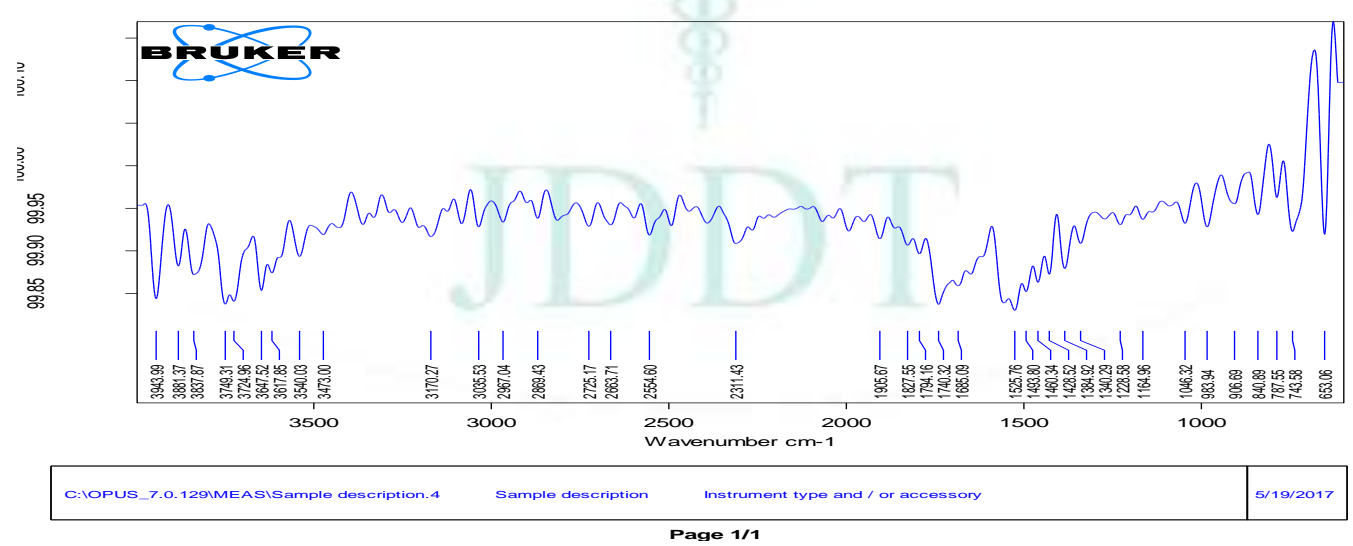

Figure 3: FTIR Spectra of Carbopol

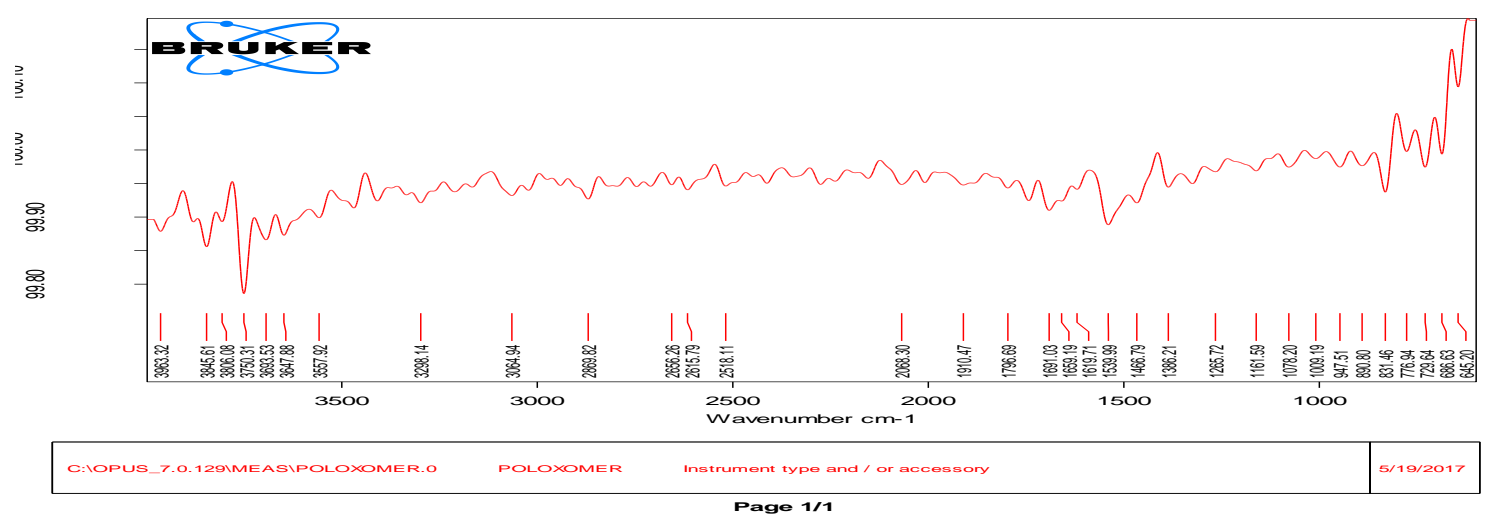

Figure 4: FTIR Spectra of Poloxamer 


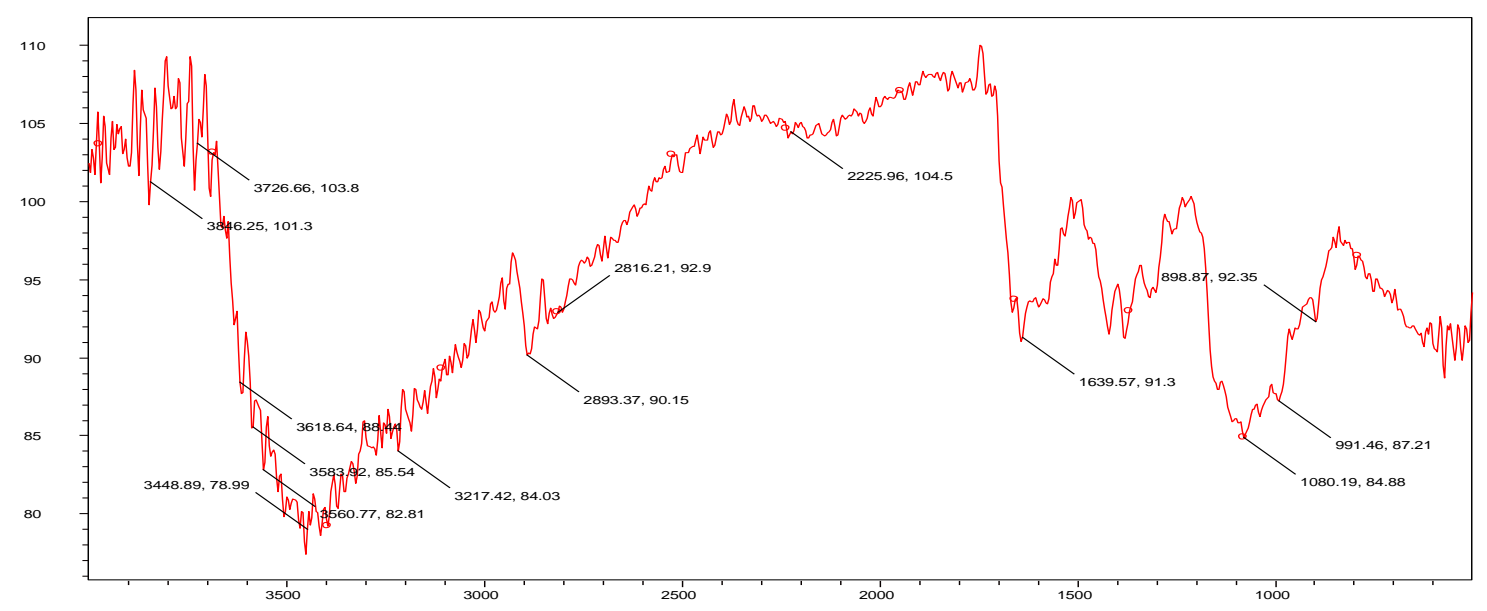

Figure 5: FTIR Spectra of chitosan

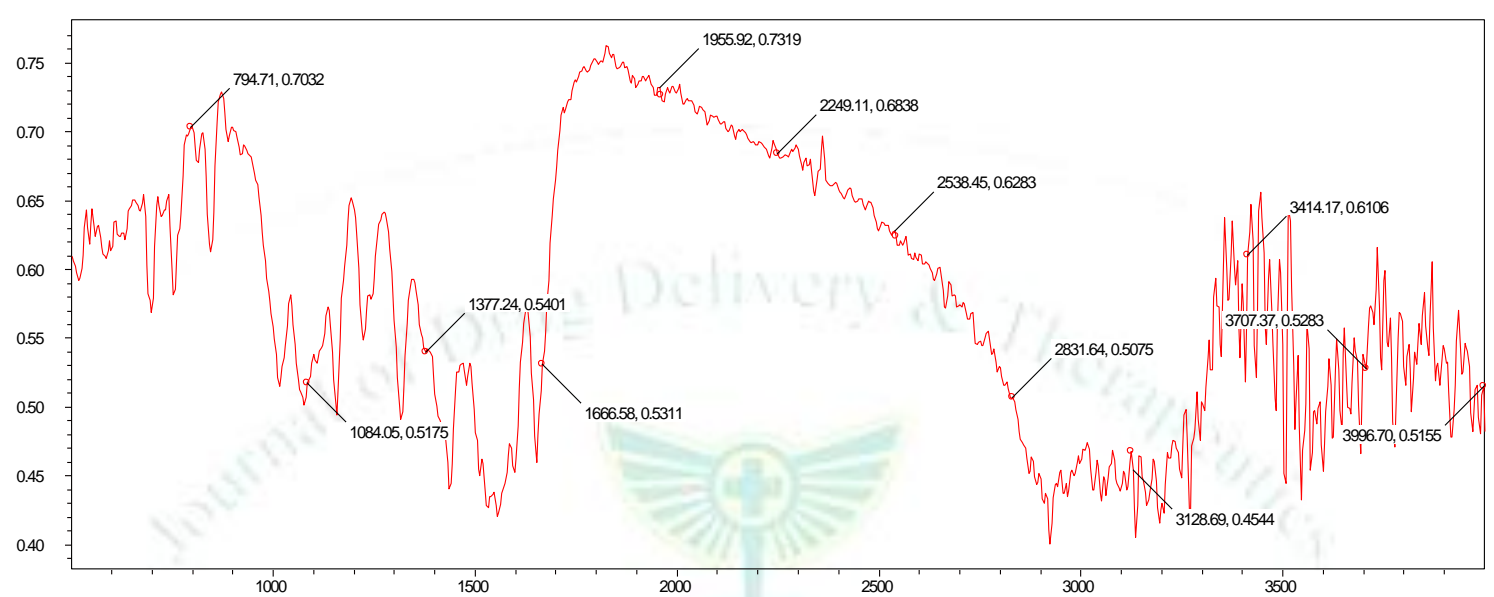

Figure 6: FTIR Spectra of HPMC

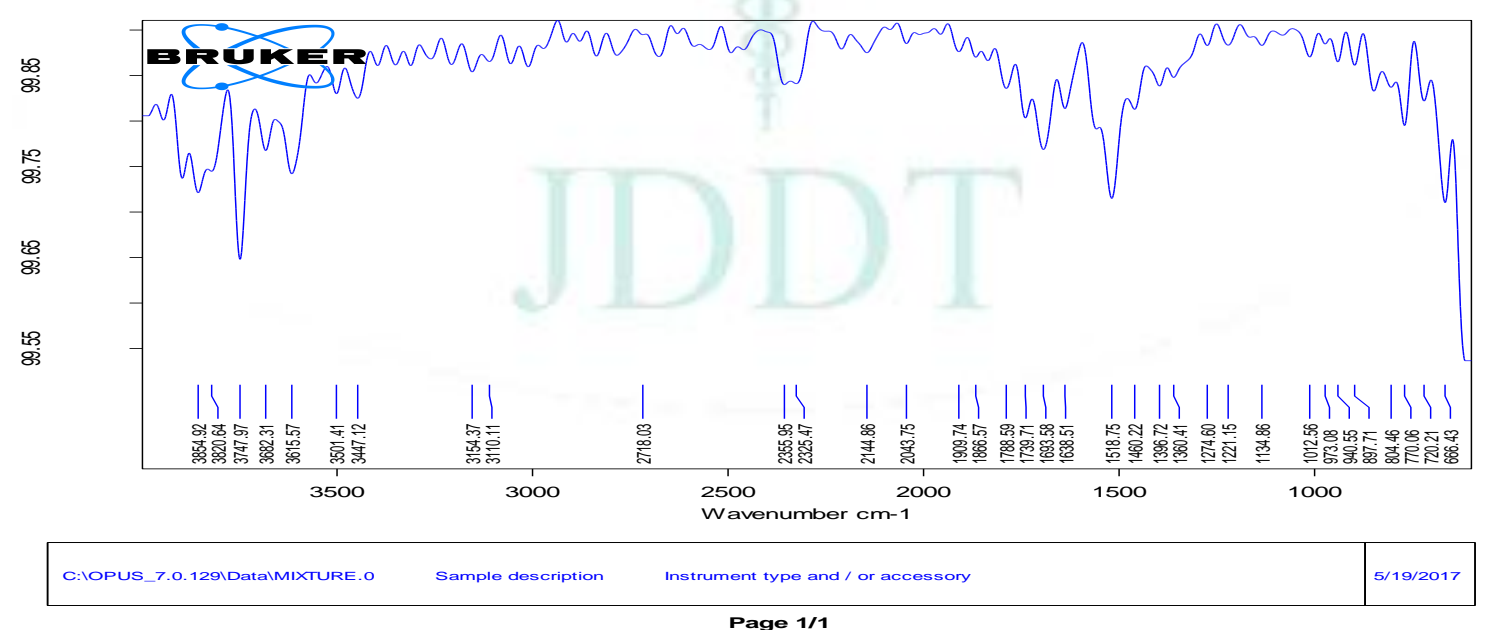

Figure 7: FTIR Spectra of Mixtures

Table 3: FTIR spectrum of observed and characteristic peak of Drug, Excipients \& Mixture of compounds

\begin{tabular}{|l|l|l|l|l|}
\hline \multirow{2}{*}{$\begin{array}{c}\text { FTIR } \\
\text { Spectrum }\end{array}$} & \multicolumn{2}{|c|}{ IR absorption bands (cm-1) } & Bond & Functional group \\
\cline { 2 - 5 } & \multicolumn{1}{|c|}{ Observed peak } & $\begin{array}{l}\text { Characteri } \\
\text { stic peak }\end{array}$ & & \\
\hline \multirow{4}{*}{ Ramipril } & $3678.49,3616.39,3562.90,3453.48,3384.85$. & $3000-3700$ & O-H stretch & Alkenes, aromatic \\
\cline { 2 - 5 } & $2907.11,2761.87,2720.98$. & $2500-3000$ & C-H stretch & Alkenes, aromatic ring \\
\cline { 2 - 5 } & $2558.16,2360.72,2303.70$. & $2100-2660$ & C=C stretch & Alkynes \\
\cline { 2 - 5 } & $\begin{array}{l}1707.13,1644.98,1462.75, \\
\text { TPP }\end{array}$ & $600-1500$ & C-Cl stretch & Alkenes \\
\hline
\end{tabular}




\begin{tabular}{|c|c|c|c|c|}
\hline & $3215.31,3150.70$ & $3100-3330$ & N-H strceh & Aromatic ring \\
\hline & $\begin{array}{l}2978.58,2871.58,2818.31,2700.81,2598.57,2546 \\
.08\end{array}$ & $2500-3000$ & C-H stretch & Alkenes , aromatic ring \\
\hline & $2498.65,2393.58,2281.52,2212.79$ & $2100-2660$ & $\mathrm{C}=\mathrm{C}$ stretch & alkynes \\
\hline Carbopol & $\begin{array}{l}3647.52,3617.85,3540.03,3473.00,3170.27,3035 \\
.53\end{array}$ & $3000-3700$ & O-H strech & Alkenes,aromaric \\
\hline & $2967.04,2869.43,2725.17,2663.71,2554.60$ & $2500-3000$ & C-H strech & Alkenes,aromaric ring \\
\hline & $\begin{array}{l}1493.80,1046.32,983.94,906.69,840.89,789.55,7 \\
43.58,653.06\end{array}$ & $600-1500$ & C-Cal strech & Alkanes \\
\hline Poloxamer & $3693.53,3647.88,3557.92,3298.14,3064.94$ & $3000-3700$ & O-H stretch & Alkenes,aromaric \\
\hline & $2869.82,2656.26,2615.79,2518.11$ & $2500-3000$ & C-H stretch & Alkenes, aromaric ring \\
\hline & $\begin{array}{l}1466.79,1386.21,1265.72,1161.59,1078.20,1009 \\
.19,947.51,890.80,831.46,776.94,729.64,686.63, \\
645.20\end{array}$ & $600-1500$ & C-Cl stretch & Alkenes \\
\hline Chitosan & $3618.64,3583.92,3448.89,3560.77$ & $3000-3700$ & $\mathrm{O}-\mathrm{H}$ stretch & Alkenes, aromatic \\
\hline & 3217.42 & $3010-3300$ & $\mathrm{~N}-\mathrm{H}$ stretch & aromatic \\
\hline & 2893.37,2225.96, & $2850-2960$ & C-H stretch & alkanes \\
\hline & 1639.57 & $1600-1900$ & $\mathrm{C}=\mathrm{O}$ stretch & Aldehydes, ketones, \\
\hline HPMC & 794.71 & $600-1500$ & C-Cl stretch & Alkenes \\
\hline & 1084.05 & $1000-1300$ & C-O stretch & Alcohols, ethers \\
\hline & 1666.58 & $1660-1580$ & $\mathrm{C}=\mathrm{O}$ stretch & Alkenes \\
\hline & $2249.11,2538.45$ & $2100-2660$ & $\mathrm{C}=\mathrm{C}$ stretch & Alkynes \\
\hline $\begin{array}{l}\text { Mixture of } \\
\text { compounds }\end{array}$ & $\begin{array}{l}3682.31,3615.57,3501.41 \\
3447.12,3154.37,3110.11\end{array}$ & $3000-3700$ & O-H stretch & Alkenes, aromatic. \\
\hline & 2718.03 & & C-H stretch & Alkenes, aromatic ring \\
\hline & $\begin{array}{l}2355.95,2325.47,2144.86, \\
2043.75\end{array}$ & $2100-2660$ & $\mathrm{C}=\mathrm{C}$ stretch & Alkynes \\
\hline & $1739.71,1693.58$ & $1680-1760$ & $>\mathrm{C}=\mathrm{O}$ & Aldehydes, ketones. \\
\hline
\end{tabular}

\section{DSC spectra:}

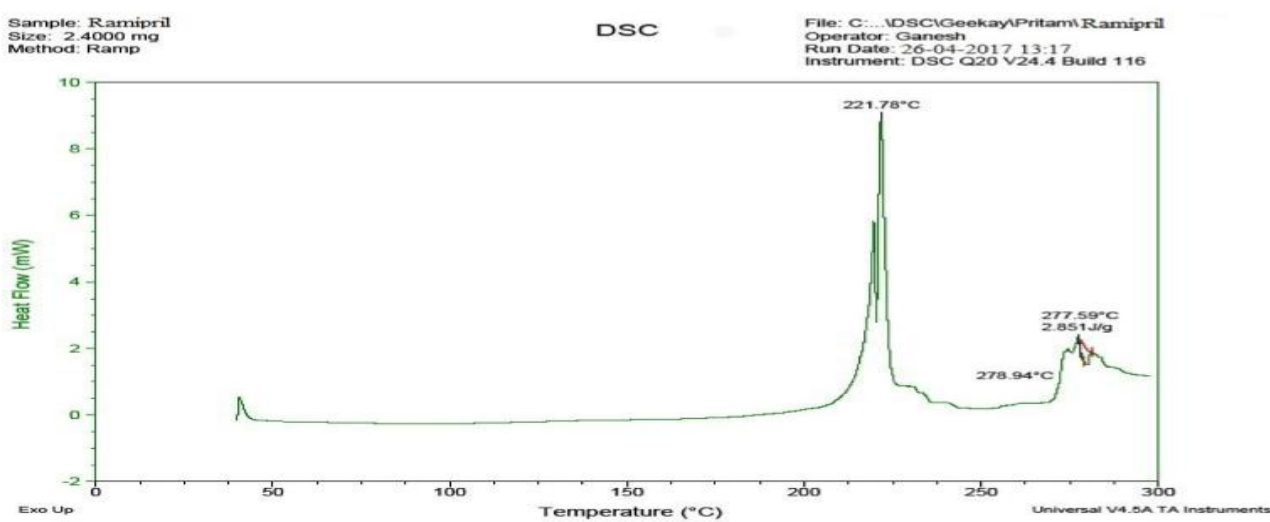

Figure 8: DSC Spectrum of Ramipril

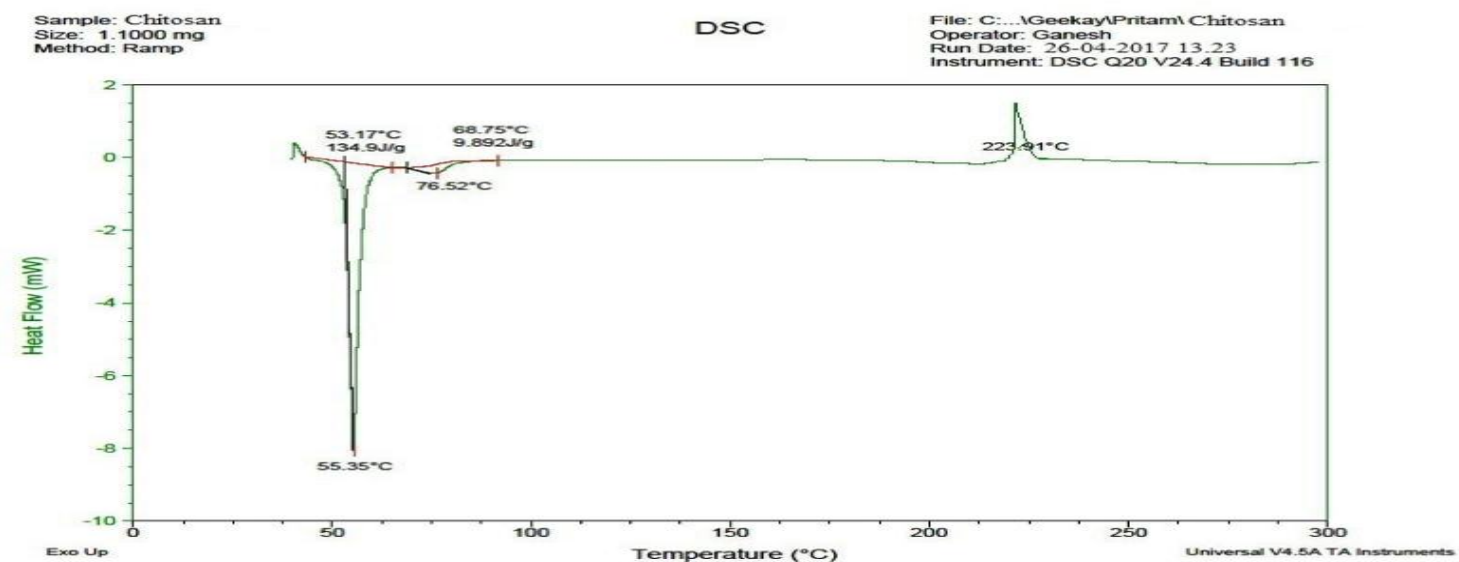

Figure 9: DSC Spectrum of Chitosan 


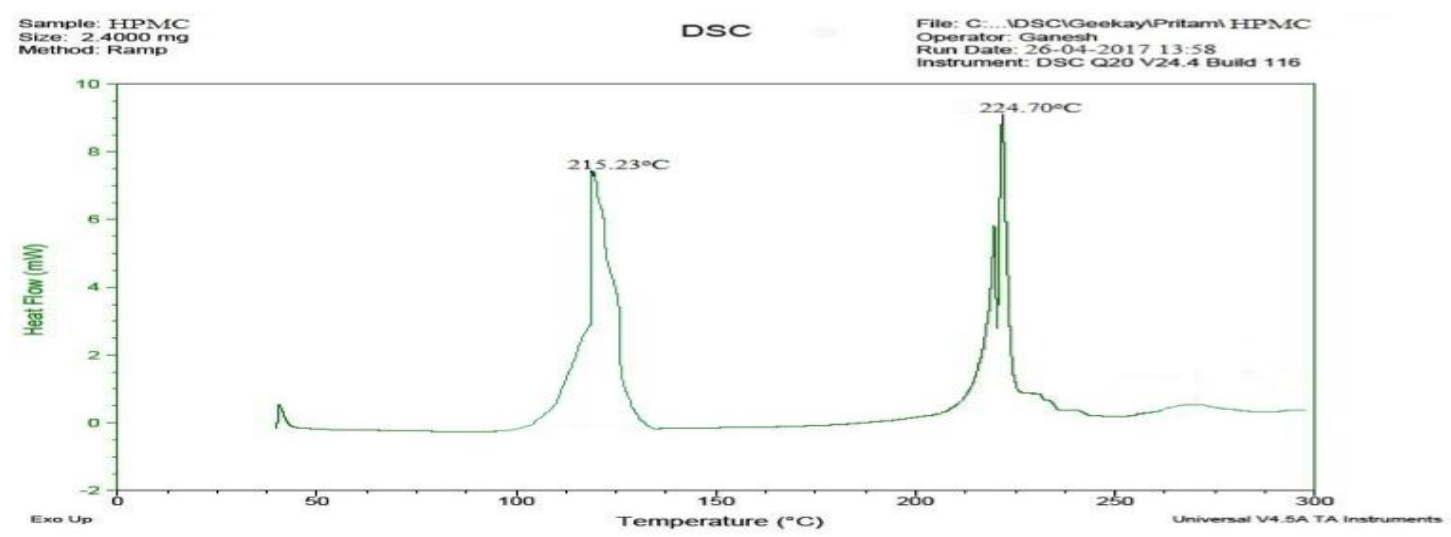

Figure 10: DSC Spectrum of HPMC

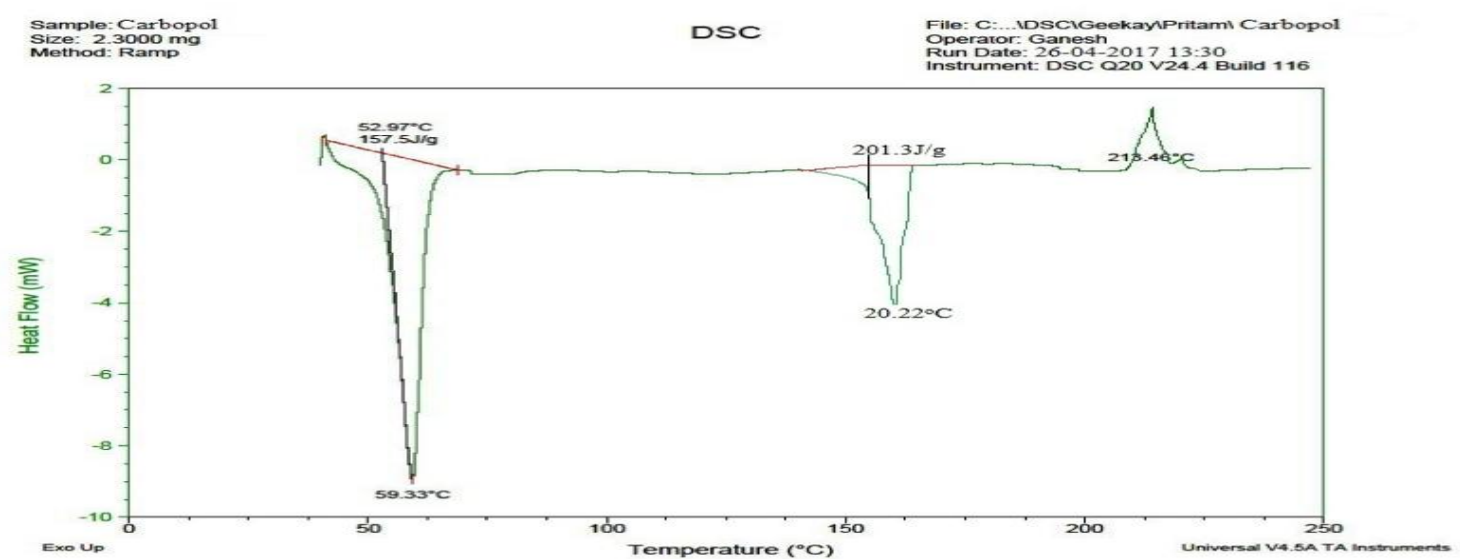

Figure 11: DSC Spectrum of Carbopol

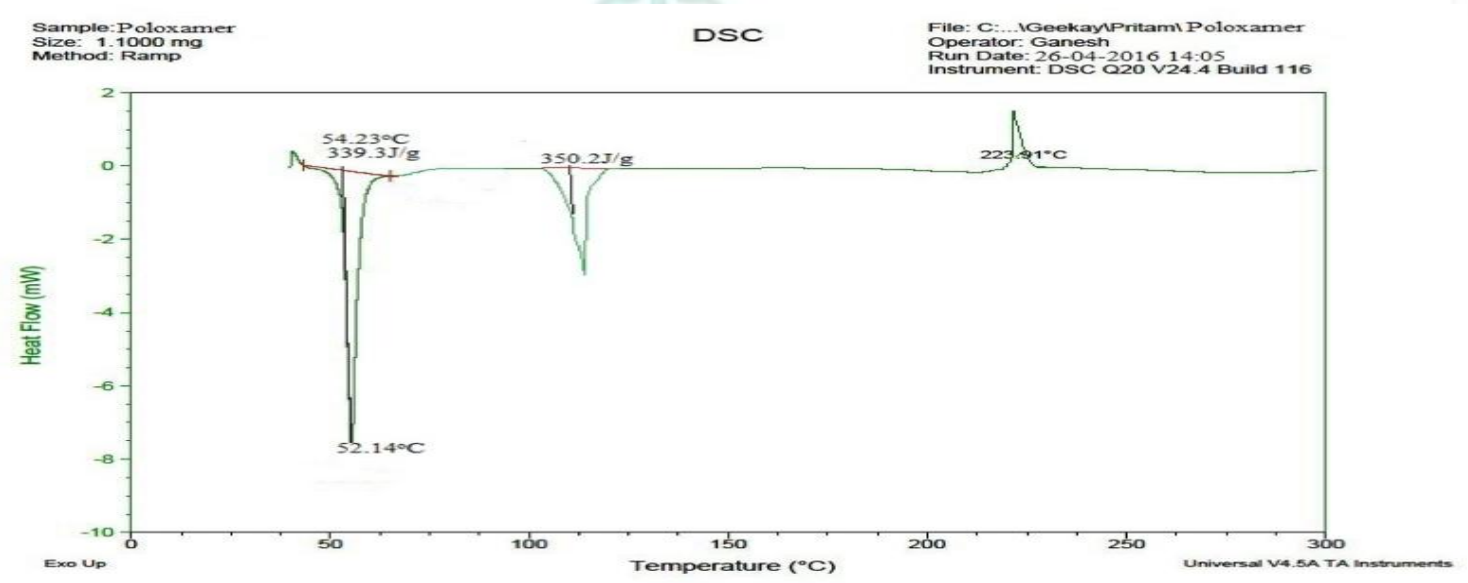

Figure 12: DSC Spectrum of Poloxamer

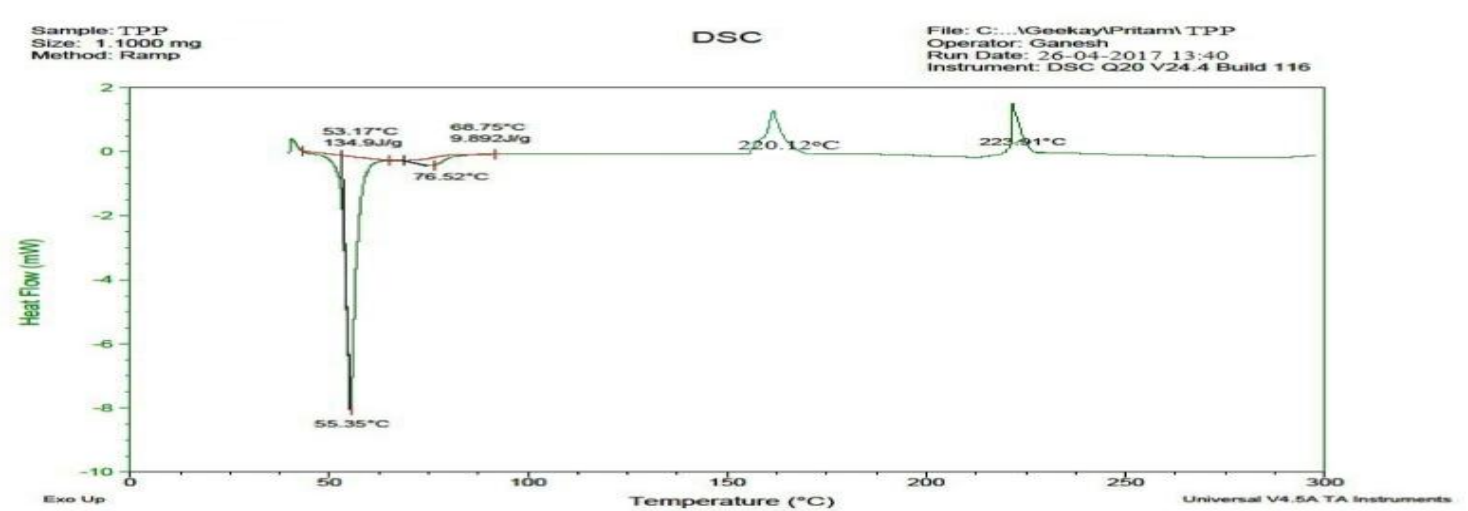

Figure 13: DSC Spectrum of TPP 


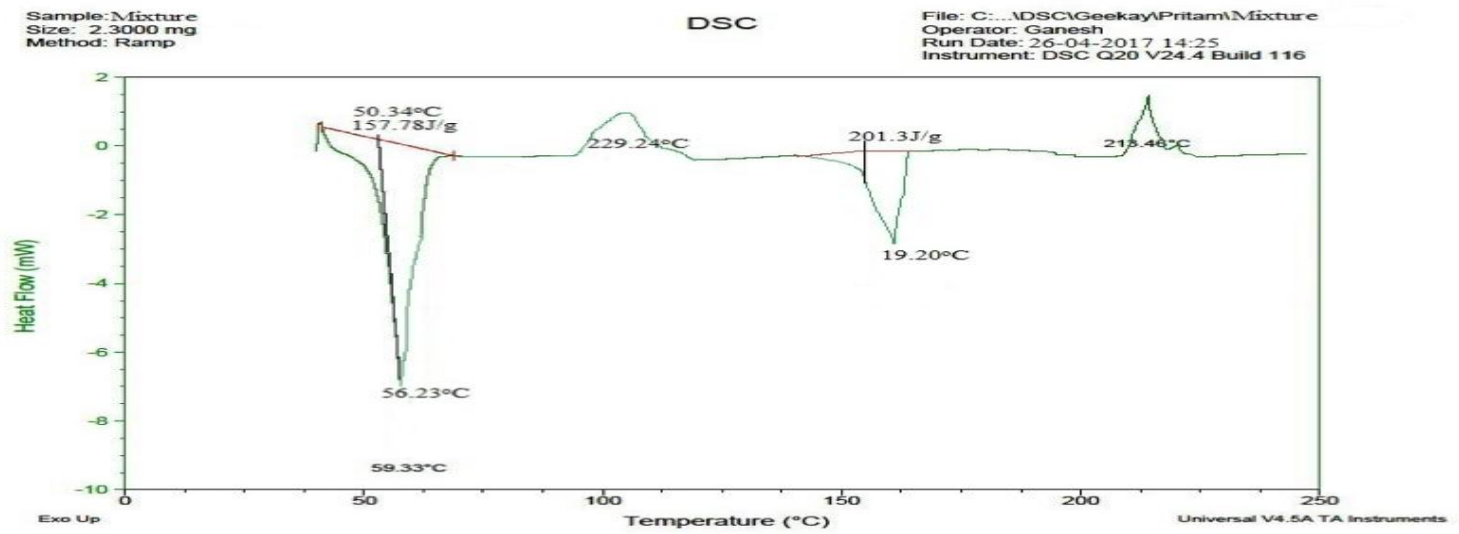

Figure 14: DSC Spectrum of Mixtures

Table 4: DSC Spectrum of ramipril, Excipients \& Mixtures

\begin{tabular}{|l|l|l|l|}
\hline SI.No & Ingredients & Endothermic peak & Exothermic peak \\
\hline $\mathbf{1}$ & Ramipril & $2.8515 \mathrm{~J} / \mathrm{g} \& 277.59^{\circ} \mathrm{C}$ & -- \\
\hline $\mathbf{2}$ & Chitosan & $223.91{ }^{\circ} \mathrm{C}$ & $55.35{ }^{\circ} \mathrm{C}$ \\
\hline $\mathbf{3}$ & Hydroxyl propyl methyl cellulose & $224.70^{\circ} \mathrm{C} \& 215.23^{\circ} \mathrm{C}$ & -- \\
\hline $\mathbf{4}$ & Carbopol & $52.96^{\circ} \mathrm{C} / 157.5 \mathrm{~J} / \mathrm{g}$ & $20.22{ }^{\circ} \mathrm{C} / 201.3 \mathrm{~J} / \mathrm{g}$ \\
\hline $\mathbf{5}$ & Poloxamer & $54.23^{\circ} \mathrm{C} / 339.3 \mathrm{~J} / \mathrm{g}$ & $223.91{ }^{\circ} \mathrm{C} / 350.2 \mathrm{~J} / \mathrm{g}$ \\
\hline $\mathbf{6}$ & TPP(Pentasodium tripolyphosphate) & $53.17^{\circ} \mathrm{C} / 134.9 \mathrm{~J} / \mathrm{g}$ & $220.1^{\circ} \mathrm{C}$ \\
\hline $\mathbf{7}$ & Mixtures & $229.24^{\circ} \mathrm{C} / 201.3 \mathrm{~J} / \mathrm{g}$ & $50.34{ }^{\circ} \mathrm{C} / 157.78 \mathrm{~J} / \mathrm{g}$ \\
\hline
\end{tabular}

Evaluation of ramipril transdermal patchs

\section{Physicochemical Evaluation of Films}

Thickness of the Patch: The thickness ranged between $0.11 \pm 0.05 \mathrm{~mm}$ to $0.19 \pm 0.07 \mathrm{~mm}$, which indicates that they are uniform in thickness as shown in the Table 5.

Weight Variation: The different batches of formulations weights variations were relatively good uniformity of weight variations among the various batches was observed, with all formulations and ranged from $1.40 \pm 1.2 \%$ to $1.78 \pm 2.0 \%$. The results indicate that the process employed to prepare patches in this study was capable of producing patches with uniform drug content and minimal patch variability. As shown in the Table 5.

Moisture Uptake: Moisture content and moisture uptake studies indicated that the increase in the concentration of hydrophilic polymer was directly proportional to the increase in moisture content and moisture uptake of the patches. The moisture content of the prepared formulations was low, which could help the formulations remain stable and reduce brittleness during long term storage. The moisture uptake of the formulations was also low, which could protect the formulations from microbial contamination and reduces bulkiness. As shown in the Table 5.

Flatness: The flatness study showed that all the formulations had the same strip length before and after their cuts, indicating 99\% flatness. Thus, no amount of constriction was observed; all patches had a smooth, flat surface; and that smooth surface could be maintained when the patch was applied to the skin. As shown in the Table 5 .

Determination of Tensile Strength: The Tensile strength of the TNPGF1 to TNPGF9 shows the 10.14 \pm 1.19 to $12.78 \pm 2.45$ shows the excellent viscosity. As shown in the Table 5.

Folding Endurance: Folding endurance test results indicated that the patches would not break and would maintain their integrity with general skin folding when applied. As shown in the Table 5.

Water Vapour Transmission (WVT) Rate: The WVTR was found to be TNPGF1 to TNPGF9 $4.87 \pm$ 0.45 to $1.23 \pm 0.21$. As shown in the table 5 .

Drug Content Determination: The total amount of drug is present in the transdermal patches of TNPGF1 to TNPGF9 was found to be $90.5 \pm 0.3 \%$ to $98.5 \pm 0.1 \%$. As shown in the table 5.

In vitro release drug diffusion studies were performed using modified Franz diffusion cell

In vitro release studies can be performed in a modified Franz diffusion cell over a period of time 5 hours. At specific time intervals, aliquots of samples containing the released drug are taken from the acceptor compartment and are quantified using a suitable method of determination Such as UV VISIB spectroscopy Ramipril $=2 \max 219$. The sink condition is usually maintained by replacing the volume of aliquots taken by similar volumes of the buffer to resemble constant clearance of drugs from their physiological site of action. The drug release parameters as shown in table 6 . 
Table 5: Physicochemical Evaluations of Films

\begin{tabular}{|l|l|l|l|l|l|l|l|l|l|}
\hline & TNPG1 & TNPG2 & TNPG3 & TNPG4 & TNPG5 & TNPG6 & TNPG7 & TNPG8 & TNPG9 \\
\hline thickness & $0.11 \pm$ & $0.12 \pm$ & $0.13 \pm$ & $0.15 \pm$ & $0.14 \pm$ & $0.18 \pm$ & $0.11 \pm$ & $0.13 \pm$ & $0.19 \pm$ \\
& 0.03 & 0.05 & 0.04 & 0.06 & 0.01 & 0.01 & 0.05 & 0.02 & 0.07 \\
\hline Weight & $1.65 \pm$ & $1.78 \pm$ & $1.61 \pm$ & $1.65 \pm$ & $1.22 \pm$ & $1.40 \pm$ & $1.55 \pm$ & $1.65 \pm$ & $1.65 \pm$ \\
variation & 1.5 & 2.0 & 1.0 & 1.5 & 2.5 & 1.2 & 0.5 & 1.5 & 1.5 \\
\hline Moisture & $3.105 \pm$ & $2.125 \pm$ & $3.135 \pm$ & $2.145 \pm$ & $3.155 \pm$ & $4.24 \pm$ & $2.135 \pm$ & $3.145 \pm$ & $1.123 \pm$ \\
uptake & 0.15 & 0.25 & 0.35 & 0.25 & 0.45 & 0.23 & 0.15 & 0.35 & 0.65 \\
\hline Flatness\% & $95 \%$ & $94 \%$ & $96 \%$ & $95 \%$ & $98 \%$ & $99 \%$ & $98 \%$ & $96 \%$ & $95 \%$ \\
\hline Tensile & $11.11 \pm$ & $10.14 \pm$ & $11.12 \pm$ & $11.11 \pm$ & $12.11 \pm$ & $11.12 \pm$ & $12.78 \pm$ & $2.56 \pm$ & $11.76 \pm$ \\
strength(psi) & 1.11 & 1.19 & 2.12 & 1.18 & 2.01 & 2.00 & 2.45 & 2.67 & 2.12 \\
\hline Folding & $130.1 \pm 0.2$ & $120.5 \pm 3$. & $164.2 \pm 2$. & $240.1 \pm 3$. & $150.2 \pm 2$. & $199 \pm$ & $210.2 \pm 2$ & $310.2 \pm 3.2$ & $206 \pm$ \\
endurance & 2 & 20 & 00 & 10 & 10 & 1.00 & .10 & 0 & 3.10 \\
\hline Water vapour & $3.67 \pm$ & $2.68 \pm$ & $4.67 \pm$ & $1.23 \pm$ & $2.12 \pm$ & $3.00 \pm$ & $2.12 \pm$ & $3.80 \pm$ & $4.87 \pm$ \\
transmission & 0.22 & 0.12 & 0.24 & 0.21 & 0.42 & 0.22 & 0.12 & 0.23 & 0.45 \\
\hline Drug content & $95.1 \pm$ & $93.7 \pm$ & $90.5 \pm$ & $91.5 \pm$ & $92.2 \pm$ & $98.5 \pm$ & $93.1 \pm$ & $94.2 \pm$ & $88.2 \pm 0.2$ \\
& 0.2 & 0.4 & 0.3 & 0.2 & 0.4 & 0.1 & 0.2 & 0.3 \\
\hline
\end{tabular}

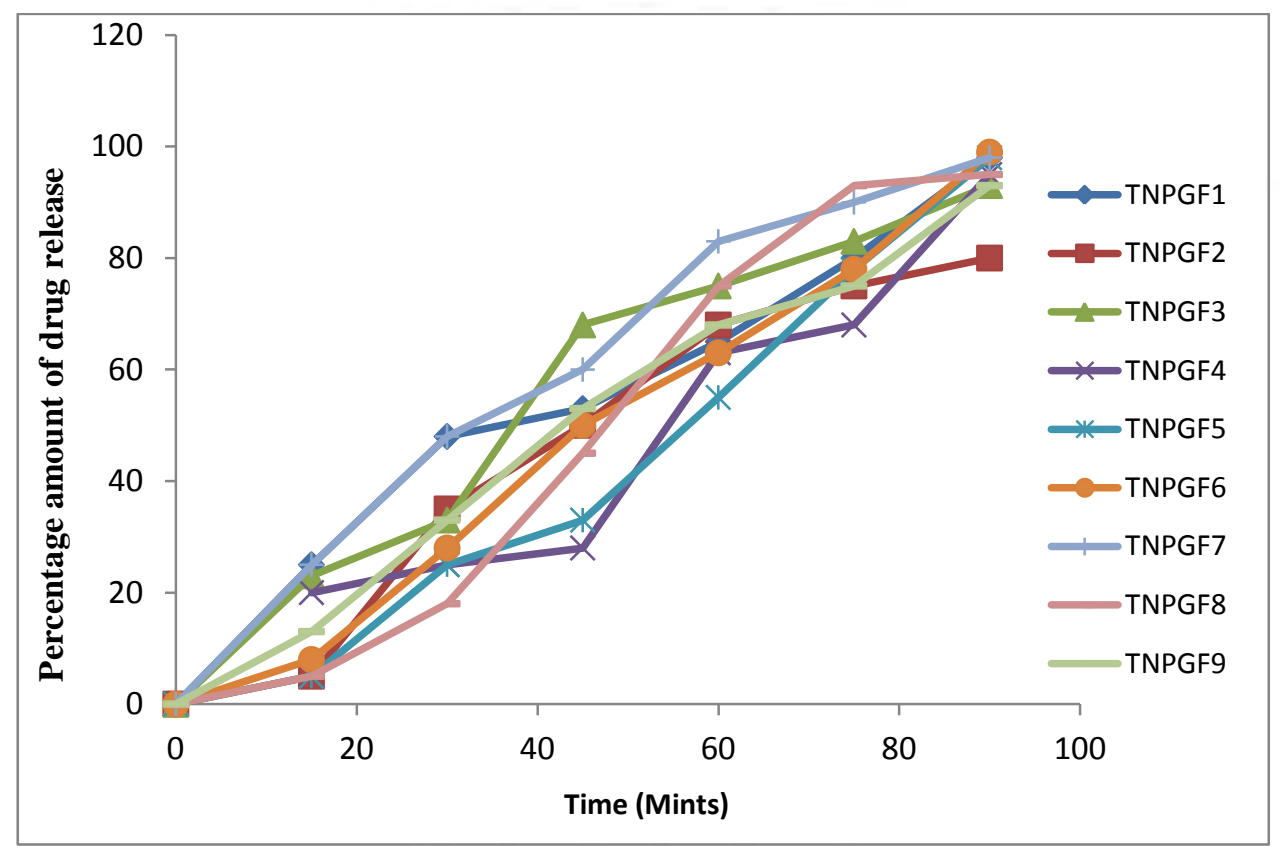

Figure 15: Cumulative \% amount of drug release of Transdermal patch of Ramipril loaded chitosan nanoparticles dispersed in carobopol gels TNPGF1 to TNPGF9

Table 6: Release order kinetics of Transdermal patch of Ramipril loaded chitosan nanoparticles dispersed in carobopol gels TNPGF1 to TNPGF9

\begin{tabular}{|l|l|l|l|l|l|l|l|l|}
\hline \multirow{2}{*}{ F. Code } & \multicolumn{2}{|c|}{ Zero order } & \multicolumn{2}{c|}{ First order } & \multicolumn{2}{c|}{ Higuchi } & \multicolumn{2}{l|}{ Korse meyer pappas } \\
\cline { 2 - 9 } & $\mathrm{R}^{2}$ & $\mathrm{M}$ & $\mathrm{R}^{2}$ & $\mathrm{M}$ & $\mathrm{R}^{2}$ & $\mathrm{M}$ & $\mathrm{R}^{2}$ & $\mathrm{M}$ \\
\hline TNPG1 & 0.973 & 10 & 0.596 & 0.024 & 0.958 & 98.73 & 0.951 & 1.526 \\
\hline TNPG2 & 0.952 & 9.821 & 0.692 & 0.026 & 0.902 & 95.12 & 0.983 & 1.558 \\
\hline TNPG3 & 0.949 & 10.47 & 0.643 & 0.025 & 0.935 & 103.6 & 0.964 & 1.539 \\
\hline TNPG4 & 0.939 & 9.940 & 0.706 & 0.025 & 0.814 & 92.11 & 0.963 & 1.490 \\
\hline TNPG5 & 0.973 & 11.13 & 0.771 & 0.027 & 0.812 & 101.1 & 0.12 & 0.005 \\
\hline TNPG6 & 0.986 & 11.66 & 0.785 & 0.029 & 0.858 & 108.3 & 0.995 & 1.56 \\
\hline TNPG7 & 0.951 & 29.10 & 0.699 & 0.032 & 0.920 & 284.9 & 0.979 & 1.789 \\
\hline TNPG8 & 0.955 & 12.32 & 0.790 & 0.029 & 0.820 & 113.6 & 0.993 & 1.584 \\
\hline TNPG9 & 0.988 & 10.41 & 0.749 & 0.028 & 0.919 & 99.97 & 0.985 & 1.538 \\
\hline
\end{tabular}




\section{CONCLUSION}

The present work showed that transdermal delivery system for ramipril based on chitosan nanoparticles dispersed into gel was successfully prepared and characterized. There is no Incompatibility between drug and polymers by performing FTIR and DSC. To characterize the rate controlling membrane of transdermal patches. The thickness ranged between TNPGF1 to F9 $0.11 \pm 0.05 \mathrm{~mm}$ to $0.19 \pm 0.07 \mathrm{~mm}$, which indicates that they are uniform in thickness. The different batches of formulations weights variations were relatively good uniformity of weight variations among the various batches was observed, with all formulations and ranged from $1.40 \pm 1.2 \%$ to $1.78 \pm$ $2.0 \%$. The flatness study showed that all the formulations had the same strip length before and after their cuts, indicating $99 \%$ flatness. The Tensile strength of the TNPGF1 to TNPGF9 shows the $10.14 \pm 1.19$ to

\section{REFERENCES:}

1. Amjad M, Ehtheshamuddin M, Chand S, Hanifa, Sabreesh M, Asia R, Kumar GS, Formulation And Evaluation Of Transdermal Patches Of Atenolol Arpb, 2011; 1(2):109-119

2. Sujitha B, Krishnamoorthy B, Muthukumaran M Formulation and Evaluation of Piroxicam Loaded Ethosomal Gel for Transdermal Delivery Int J Adv Pharm Gen Res, 2014; 2(1):34-45

3. Nirja, Jalwal P, Saini J, Mamta, Ritu, Formulation and Evaluation of Transdermal Drug Delivery System For Ibuprofen, IJPPR 2013; 4(2).

4. Kaur M, Bhatia A, Sethi D, Kaur G, Vig K, Hypoglycemic potential of probiotic DNA loaded chitosan nanoparticles: an in vivo study. Journal of Drug Delivery and Therapeutics, 2017; 7(2):70-76. doi:10.22270/jddt.v7i2.1405

5. Samy AM, Ghorab MM, Shadeed SG, Mazyed EA, Formulation And Evaluation Of Differefnt Transdermal Drug Delivery Systems Of Ketoprfen, International Journal Of Pharmacy And Pharmaceutical Sciences, 2013; Vol 5, Suppl 2.

6. Vijayakumar KS, Parthiban S, Senthilkumar GP, T. Tamiz mani, Formulation And Evaluation Of Gliclazide Loaded Ethosomes As Transdermal Drug Delivery Carriers Asian Journal of Research in Biological and Pharmaceutical Sciences. 2014; 2(2):89 - 98.

7. Anil Reddy B et al., In Vitro Characterization and Evaluation of Transdermal Drug Delivery System for Metoprolol Tartarate Jprhc, 2013; 2(4):325-329.

8. Ting Li, Changshun Ren, Manli Wang, Ligang Zhao, Ximeng Wang, Liang Fang, Optimized preparation and evaluation of indomethacin transdermal patch Asian Journal of Pharmaceutical Sciences 2007; 2(6):249-259 249.

9. Yanamandra S, Venkatesan N, Gowda Kadajji V, Wang Z, Manish Issar, Guru V. Betageri, and Proliposomes as a drug delivery system to decrease the hepatic first-pass metabolism: Case study using a model drug European Journal of Pharmaceutical Sciences, 2014; 64:26-36.

10. Sveinung G. Ingebrigtsen, Natasaskalko Basnet, Cristiane de Albuquerque Cavalcanti Jacobsen, Ann Mari Holsæter Successful co-encapsulation of benzyl peroxide and chloramphenicol in liposomes by a novel manufacturing method dual asymmetric centrifugation European Journal of Pharmaceutical Sciences, 2017; 97:192-199.
$12.78 \pm 2.45$ shows the excellent viscosity. The total amount of drug is present in the transdermal patches of TNPGF1 to TNPGF9 was found to be $90.5 \pm 0.3 \%$ to $98.5 \pm 0.1 \%$. In-vitro Franz's diffusion drug Release Studies among all formulations the best formulation was TNPGF6. The drug release through the transdermal patches of Ramipril follows First order kinetics with diffusion controlled mechanism. Effect of penetration enhancer like dimethyl sulfoxide has been checked on in-vitro permeation of drug and was found to be effective. Gels may create a drug reservoir to provide the system with ramipril over long period of time to control the blood pressure.

Acknowledgement: I would like thank my Guide Mr. Y. Ramesh, M. Pharm., (Ph.D) for his encouragement and suggestions to carry out my research work successfully.

11. Karthik Y. Janga, RajuJukanti, Ashok Velpula, SharathSunkavalli, Suresh Bandari, PrabhakarKandadi, Prabhakar Reddy Veerareddy Bioavailability enhancement of zaleplon via proliposomes: Role of surface charge European Journal of Pharmaceutics and Biopharmaceutics, 2012; 80:347-357

12. ZeljkaVanic, Odon Planinsek, Natasakalko-Basnet, IngunnTho, Tablets of pre- liposome's govern in situ formation of liposomes: Concept and potential of the novel drug delivery system, European Journal of Pharmaceutics and Biopharmaceutics, 2014; 88:443-454.

13. Dingler A, Gohla S. Production of solid lipid nanoparticles, scaling up feasibilities. J Microencapsul, 2002, 19: 11-16.

14. Freitas C, Müller RH.. Correlation between long-term stability of solid lipid nanoparticles (SLN) and crystallinity of the lipid phase. Eur J Pharm Biopharm, 1999; 47:125-132.

15. Friedrich I, Reichl S, Muller-Goymann CC. Drug release and permeation studies of nanosuspensions based on solidified reverse micelle solutions, Int J Pharm, 2005; 305:167-175.

16. Kalam MA, Sultana Y, Samad A, Ali A, Aqil M, Sharma M, Mishra AK, Gelrite-based in-vitro gelation ophthalmic drug delivery system of gatifloxacin, J Disp Sci Tech, 2008; 29:8996.

17. Liu J, Gong T, Wang C, Zhong Z, Zhang Z, Solid lipid nanoparticles loaded with insulin by sodium cholatephosphatidylcholine- based mixed micelles: preparation and characterization. Int J Pharm, 2007; 340:153-162.

18. Kaur M, Bhatia A, Sethi D, Kaur G, Vig K. Hypoglycemic potential of probiotic DNA loaded chitosan nanoparticles: an in vivo study. Journal of Drug Delivery and Therapeutics, 2017; 7(2):70-76. doi:10.22270/jddt.v7i2.1405

19. Noha S. El-Salamouni, Ragwa MF, AmalH. El Kamel, Effect of sterilization on the physical stability of brimonidine loaded solid lipid nanoparticles and nanostructured lipid carriers. International journal of pharmaceutics, 2015; 49(6):976-983.

20. Umaretiya GM, Patel PR, Patel J, formulation and characterization of solid lipidnanoparticles dry powder inhaler containing triamcinolone acetonide. International journal of research in pharmacy and chemistry. 2011; 1(3):221-232. 